\title{
LA PROBLEMÁTICA DE LA VEJEZ EN EL DERECHO ARGENTINO: razones para la construcción del derecho de la ancianidad
}

\author{
María Isolina Dabove ${ }^{1}$
}

\section{Resumen}

La incorporación del Derecho al campo de la Gerontología ha sido, en verdad, muy reciente. Hace tan sólo unos 25 años que comenzó en el mundo el desarrollo del proceso de formalización de los derechos humanos de los ancianos, con carácter integral. Este fenómeno, junto a las crecientes necesidades sociales que plantea la población envejecida en Argentina, han sido responsables de la reciente creación de una especialidad jurídica transversal, que hemos dado en llamar: Derecho de la Ancianidad. La continuidad vital, la privacidad y la participación constituyen sus principios rectores, dando sustento al despliegue de los derechos fundamentales de autonomía, participación y crédito de las personas de edad.

Palabras clave: Vejez. Derecho Argentino. Derecho de la Ancianidad. Derechos fundamentales de autonomía, participación y crédito de las personas de edad.

\section{Introducción}

El Derecho ha sido una de las últimas disciplinas en incorporarse al campo de la Gerontología, y lo ha hecho muy recientemente. Aunque es cierto que la Seguridad Social se ha ocupado de la cuestión de la vejez desde el siglo XIX; sin embargo, hace tan sólo unos 25 años que ha comenzado el desarrollo de un proceso de formalización de los derechos de los ancianos, con carácter verdaderamente integral. En efecto, la Seguridad Social ha abordado la problemática de la vejez en su dimensión de contingencia y enfermedad. Ha permitido el despliegue de importantes sistemas previsionales y asistenciales en el mundo. Pero, solo el consenso internacional del siglo XX ha podido abrir el camino hacia el reconocimiento pleno de los

1 Investigadora del Consejo de Investigaciones (CI) de la Universidad Nacional de Rosario (UNR). Directora del Centro de Investigaciones en Derecho de la Ancianidad de la Facultad de Derecho de la UNR. Profesora de Filosofía del Derecho y de Derecho de la Ancianidad de la Facultad de Derecho de la UNR y de la Universidad Nacional del Centro de la Provincia de Buenos Aires (UNICEN). Doctora en Derecho por la Universidad Carlos III de Madrid. E-mail: mdabove@sede.unr.edu.ar 
derechos humanos de las personas de edad, sin distinción de credos, razas, orientación sexual o diversidad cultural (DABOVE, 2002).

Este fenómeno de formalización, junto a las crecientes necesidades sociales que plantea la población senescente en Argentina, como veremos, han sido responsables de la reciente creación de una especialidad jurídica, que hemos dado en llamar: Derecho de la Ancianidad. Los apartados que siguen están destinados a estudiar los principios que la informan y su contenido, cuáles son las razones que influyeron en su configuración y qué sustentos jurídicos encontramos hoy en el plano internacional, regional y nacional, para su sostenimiento.

\section{La Vejez en el Derecho Argentino}

Como sabemos, en la actualidad ser viejo significa formar parte de un segmento humano vulnerable, al que el Derecho califica como "sujeto frágil”. Lamentablemente, Argentina no escapa de esta “tradición”, razón por la cual cabe decir que, en el Derecho occidental, ser viejo todavía implica vivir sujeto a una triple situación de debilidad: fáctica, normativa y valorativa. Por ello, siguiendo las enseñanzas de la teoría trialista del Derecho ${ }^{2}$ bien puede afirmarse que: la dinámica jurídica social torna vulnerable al viejo, en tanto lo estereotipa y lo constriñe en su ámbito de actuación. El sistema normativo lo debilita, por no ofrecerle completamente un marco de protección jurídica adecuado a su naturaleza. Pero además, lo debilitan los valores jurídicos imperantes, cada vez que no reconocen suficientemente a la persona anciana como fin en sí (CIURO CALDANI, 1992, 1995a). Veamos un poco más de cerca este diagnóstico jurídico argentino.

En el contexto sociológico del Derecho puede observarse que ser anciano significa vivir altamente condicionado por los factores biológicos propios de este tiempo, tanto como por el conjunto de conductas de otros individuos respecto de aquél. Sobre este escenario no le resultó difícil a la cultura occidental positivista contribuir al establecimiento de fuertes vínculos no simétricos entre anciano y sociedad. Esa falta de reciprocidad es, precisamente, la que colocará al viejo en el lugar del débil, del inferior. Al propio tiempo que fomentará el desarrollo de vínculos no correspondidos, materialmente desiguales, de mutua desconfianza y extremada oposición, otorgándole carácter residual a su participación.

2 Respecto de la teoría trialista del Derecho puede verse básicamente: Goldschmidt (1987) e Ciuro Caldani (1994, 1995c, 2000). 
Así, pues, en las poblaciones occidentales no será infrecuente observar que el anciano actúe como sujeto pasivo, como recipiendario, más que como repartidor de derechos y deberes. Al tiempo que habitual será también que la sociedad construya sobre él, patrones de conductas jurídicas autoritarios, basados en razones sociales fuertemente estereotipadas (BAZO, 1993; CIURO CALDANI, 1983; ESPAÑA, 1990). La asociación de la vejez con la enfermedad, con la fealdad y la decadencia; la represión de su sexualidad, la invisibilización de su trabajo, la negativa de escucharlos, son todos ellos ejemplos muy ilustrativos de los prejuicios que aún pesan sobre las personas de edad. Sin embargo, urge también reconocer que la ancianidad provoca, al propio tiempo, reacciones sociales cargadas de profunda ambivalencia. Tal como lo ilustra la consideración política del viejo como competidor fuerte que realizó la sociedad norteamericana, a la hora de establecer el reparto público de bienes en los años noventa (DANIELS, 1988).

El análisis de la perspectiva normativa tampoco nos ofrece un panorama jurídico que contribuya de manera clara a fortalecer la condición del anciano. En la Constitución Argentina, incluso luego de la reforma de 1994, el reconocimiento de los derechos de la ancianidad resulta extremadamente débil. Sólo contamos con alguna referencia específica en un artículo que cuenta con escasa proyección inmediata, el 75 inc. 23. Así como también es aplicable el inc. 22 del mismo artículo, referido a la vigencia de los Tratados y Pactos Internacionales en materia de Derechos Humanos, en general ${ }^{3}$. El

3 Articulo 75 inc. 22 - Constitución Nacional Argentina (ARGENTINA, 2000, p. 26): “Corresponde al Congreso [ . . . ] Aprobar o desechar tratados concluidos con las demás naciones y con las organizaciones internacionales y los concordatos con la Santa Sede. Los tratados y concordatos tienen jerarquía superior a las leyes.

La Declaración Americana de los Derechos y Deberes del Hombre; la Declaración Universal de Derechos Humanos; la Convención Americana sobre Derechos Humanos, el Pacto Internacional de Derechos Económicos, Sociales y Culturales; el Pacto Internacional de Derechos Civiles y Políticos y su Protocolo Facultativo; la Convención sobre la Prevención y la Sanción del Delito de Genocidio; la Convención Internacional sobre la Eliminación de todas las Formas de Discriminación Racial; la Convención sobre la Eliminación de todas las formas de Discriminación contra la Mujer; la Convención contra la Tortura y otros Tratos o Penas Crueles, Inhumanas o Degradantes; la Convención sobre los Derechos del Niño; en las condiciones de su vigencia, tienen jerarquía constitucional, no derogan articulo alguno de la primera parte de esta Constitución y deben entenderse complementarios de los derechos y garantías por ella reconocidos. Sólo podrán ser denunciados, en su caso, por el Poder Ejecutivo nacional, previa aprobación de las dos terceras partes de la totalidad de los miembros de cada Cámara.

Los demás tratados y convenciones sobre derechos humanos, luego de ser aprobados por el Congreso, requerirán del voto de las dos terceras partes de la totalidad de los miembros de cada Cámara para gozar de la jerarquía constitucional.”.

Estud. interdiscip. envelhec., Porto Alegre, v. 13, n. 1, p. 7-26, 2008. 
art. 75 inc. 23 establece que corresponde al Congreso de la Nación, entre otras atribuciones,

[ ... ] Legislar y promover medidas de acción positiva que garanticen la igualdad real de oportunidades y de trato, y el pleno goce y ejercicio de los derechos reconocidos por esta constitución y por los tratados internacionales vigentes sobre derechos humanos, en particular respecto de los niños, las mujeres, los ancianos y las personas con discapacidad (ARGENTINA, 2000, p. 27).

Por otra parte, entre las fuentes formales existe todavía una profunda dispersión en el reconocimiento de los derechos de los ancianos. En su mayoría, las normas vigentes abordan cuestiones previsionales y, en el plano jurisprudencial, pocos son los fallos que contemplan la situación de los mayores de manera integral. Incluso, resulta habitual en este marco, que se considere a la vejez como un concepto unívoco, sinónimo de vida devaluada (DABOVE, 2002).

Frente a este panorama, en Argentina, bien afirmarse que los derechos de la ancianidad sufren una doble “capitis diminutio”. De un lado, al formar parte - en el mejor de los casos -, del grupo de derechos humanos económicos, sociales y culturales. Y, de otro, al constituir un grupo de derechos humanos bastante novedoso, de reciente plasmación (será a partir de la década del 70 cuando comienzan a ser elaborados de manera expresa), objeto más de políticas sociales coyunturales ${ }^{4}$.

Por último, el análisis valorativo del Derecho tampoco ofrece un panorama alentador respecto de la condición jurídica del anciano. Sobre todo porque en Argentina no está suficientemente desarrollado un criterio especial de justicia que permita tanto proteger a la persona de edad, como integrarla su comunidad, debidamente (BROCK, 1989; CIURO CALDANI, 1995b; ASIEL, 1991). Con mucha timidez el Derecho argentino reconoce que la vejez es un elemento relevante, a la hora de realizar los juicios de ponderación valorativa necesarios para resolver algún caso vinculado a la vejez (LÓPEZ JIMÉNEZ, 1992; DANIELS, 1981; PENNING, 1995). Además, los problemas de justicia suelen complicarse por la oposición que surge de la necesidad de satisfacer otros valores igualmente relevantes. Así, por ejemplo, el vertiginoso avance de los conocimientos pone en crisis la idea

En este sentido puede consultarse: Mendez Costa (1983); López Aranguren (1993); Dabove (1996, 2002). 
de verdad que pueda desarrollar un anciano. Sus saberes se tornan obsoletos con progresiva rapidez y poco espacio queda entonces para la comunicación intergeneracional (BEAUVOIR, 1989; DABOVE, 2002; GLASTONBURY, 1992).

Otros conflictos jurídicos relevantes en materia valorativa se desencadenan en torno a las exigencias de justicia y a las propias de la salud. Sabemos que a esta edad es posible padecer mayor número de enfermedades, y que nuestras posibilidades vitales útiles se van perdiendo. Por ello no será raro observar que se discrimine a una persona en el acceso a la asistencia sanitaria, en virtud de su edad. Mas si a ello le añadimos el problema económico de los recursos, siempre escasos, cabe cuestionarse, por ejemplo, si es legítimo dejar de administrarle a un anciano un servicio médico, para beneficiar con él a una persona con mayores posibilidades vitales - niño, adulto, joven. $\mathrm{O}$ bien: hasta qué punto se justifica la desvalorización actual de la vida de un anciano en el cálculo de las indemnizaciones por muerte, a causa su menor viabilidad para seguir viviendo y su "falta" de utilidad (FOKKEMA; UNIVERSIY, 1992).

\section{El Derecho de la Ancianidad: nueva frontera del campo jurídico}

El cuadro jurídico analizado respecto de la ancianidad, ha llevado a proponer la necesidad de construir una nueva especialidad dentro del Derecho, que hemos denominado: Derecho de la Ancianidad5. Esta rama, a mi entender, se diferencia de las demás y se caracteriza, precisamente, por la fragilidad de sus beneficiarios - según vimos -, tanto como por su contenido transversal respecto de las ramas jurídicas tradicionales. Por ello, bien puede ser definida como aquel campo del Derecho que se ocupa de abordar de manera integral las cuestiones jurídicas relacionadas con las personas de sesenta años o más - o bien que hayan entrado en edad jubilatoria -; en virtud de las características y necesidades especiales que presenta esta etapa de la vida.

Así, el Derecho de la Ancianidad estudia la condición jurídica de los ancianos en tanto sujetos de derechos constitucionales, civiles y políticos. Su situación de sujetos de derechos administrativos, procesales o penales; o bien su calidad de sujetos de derechos comerciales, laborales, sociales,

5 Un hito importante para esta materia, lo ha constituido el establecimiento del primer Centro de Investigaciones en Derecho de la Ancianidad de la República Argentina, con sede en la Facultad de Derecho de la Universidad Nacional de Rosario, en el año 2001. Este marco institucional, nos permitió a su vez, el desarrollo de una asignatura titulada, precisamente "Derecho de la ancianidad", en el marco de la Carrera de Derecho de la Universidad mencionada, a partir del año 2005.

Estud. interdiscip. envelhec., Porto Alegre, v. 13, n. 1, p. 7-26, 2008. 
educativos, recreativos y culturales. En consecuencia puede señalarse que esta nueva rama comprende el estudio de los derechos fundamentales de autonomía, participación y de crédito, que pueden serles atribuidos a las personas, cuando han comenzado a transitar la última etapa de sus vidas. Y lo hace abordando dos situaciones jurídicas que resultan centrales para todo ser humano: el derecho a ser viejo y el derecho a envejecer. El derecho a ser viejo, a mantenerse vivo, independiente y participativo, tanto como el derecho a envejecer, a obtener los recursos adecuados para vivir en justicia, una ancianidad saludable y productiva hasta el final.

La construcción de este Derecho de la Ancianidad requiere, a mi juicio, la asunción de de tres principios básicos y específicos para nuestra materia:

a) continuidad vital;

b) privacidad;

c) participación.

El principio de continuidad vital es la manifestación específica del principio de igualdad en la vejez. Significa admitir que todas las manifestaciones de la vida humana constituyen el sustrato del mundo jurídico. Implica reconocer que la vida tiene carácter pantónomo. Es una totalidad dinámica y va más allá de los fraccionamientos estancos que producen la consideración de la existencia en términos de niñez, juventud, adultez o vejez. Así, el principio de continuidad requiere que la vida de una persona sea aprehendida de manera holística, acorde con la complejidad de su desarrollo. Exige del Derecho un trato igualitario para el viejo (formal y materialmente hablando), de modo tal que el conjunto de su vida - pasada, presente y por venir -resulte valorada e incluida en sus instituciones (DABOVE, 2002).

Desde el principio de privacidad, en cambio, podemos observar que el envejecimiento es un elemento constitutivo del concepto de unicidad de la persona. Con la privacidad se abre el camino para el sostenimiento jurídico de la autonomía, la libertad y la intimidad del viejo. Se refuerza el papel de sujeto de cada anciano. Se protege, como expresa Fromm, el concepto de yoidad, el sentido de ser en el mundo, desde una subjetividad particular (FROMM, 1993).

Hay muchos tipos de ancianidad. La Gerontología suele clasificarla en cohortes de diez años entre sí. Por ello se habla de tercera, cuarta y quinta edad, haciendo referencia a las personas de 60 a 70 años, de 70 a 80 y de 80 a más edad. Pero además, la ancianidad se distingue por su género y sexualidad, clase social, estado civil, nacionalidad, condición política, 
profesión u ocupación, nivel educativo, grado de autonomía, dependencia o discapacidad que se presente en cada caso (DABOVE, 2002).

Por último, cabe señalar que el Derecho de la Ancianidad se construye con el recurso al principio de participación, sin el cual no sería posible la vida comunitaria. A través del reconocimiento de este principio, el diálogo intergeneracional tendrá lugar en el Derecho, se podrá rescatar la historia y la experiencia, la esperanza y los proyectos de la sociedad en general.

\section{Razones para la Construcción del Derecho de la Ancianidad}

El Derecho de la Ancianidad en Argentina se fue configurando, gracias al desarrollo de los Derechos Humanos y la Bioética de las décadas del cincuenta y setenta, respectivamente.

\subsection{Autonomía Material}

En el campo de los Derechos Humanos, dos fenómenos permitieron la aparición de los derechos de la ancianidad. Por un lado, la positivación internacional de los “derechos económicos, sociales y culturales”, en base a los cuales se consagraron los derechos relacionados con el trabajo y la seguridad social. Mas de otro, el desarrollo de lo que Bobbio ha dado en llamar: "el proceso de especificación". Por su intermedio, se dio lugar a la formalización de un grupo de derechos humanos, caracterizados por sus sujetos titulares. Así, en su seno, se fueron consagrando pactos internacionales relativos a los derechos de los prisioneros de guerra, de las minorías raciales, de los niños, de los enfermos, de las mujeres y de los consumidores, entre otros, que incluso han sido recogidos por la Constitución Argentina (BOBBIO, 1991).

El segundo aporte, como dijimos, proviene en cambio de la Bioética. El Derecho de la Ancianidad ha podido encontrar en su haber un interesante panorama de las exigencias valorativas requeridas por la cultura de este tiempo, como puntos de partida para su legitimación. En efecto, los principios de beneficencia y no maleficencia, el de autonomía y justicia consagrados en la década del setenta para encauzar el despliegue biotecnológico, se han ido receptando en el ámbito jurídico para resolver conflictos relativos a nuestro objeto de estudio (GRACIA, 1989; DANIELS, 1981; NINO, 1989; DABOVE, 2002). La legislación y la jurisprudencia actual poco a poco van adoptando para sí estos parámetros, logrando crear conciencia de la necesidad de fortalecer la posición de los ancianos. 
El empoderamiento emergente de estas discplinas, aunque incipiente, ya es muy útil a la ancianidad. Como diría el maestro Goldschmidt (1987), ha permitido reforzar la condición jurídica de las personas de edad frente a los demás - respecto de otros individuos o instituciones -, frente a $\underline{\underline{l o}}$ demás - es decir, respecto a las circunstancias de pobreza y enfermedad. E, incluso, respecto de sí mismo - a fin de evitar los riesgos auto-aislamiento y desintegración.

\subsection{Autonomía Formal y su Vinculación con Otras Ramas del Dere- cho}

La primera rama jurídica que se ocupo de la problemática de la ancianidad en este tiempo fue, sin dudas, el Derecho Internacional. Testimonio de esta afirmación lo constituye el Plan de Acción Internacional de Viena sobre el Envejecimiento, promulgado por la Organización de las Naciones Unidas (ONU) en 1982. En tanto que, veinte años después, se dará origen al segundo texto normativo importante: el Plan de Acción de Madrid de 2002. Ambos instrumentos constituyen los únicos textos internacionales específicos, que se ocupan de los derechos de los ancianos de manera integral. Los Planes de acción contienen una serie de recomendaciones dirigidas a los Estados firmantes, a fin de que éstos las ejecuten en función de sus posibilidades económicas, sociales y culturales. Con todo conviene adelantar también que para el Derecho vigente, estos instrumentos sólo adquirieron calidad de fuentes formales de "espectáculo o propaganda”6. Veamos brevemente los temas que abordan cada uno de ellos.

El Plan de Acción de Viena de 1982 (ASAMBLEA . . . , 1982) está estructurado en cuatro partes. Una Introducción, explicativa del contexto histórico y jurídico que le da origen. La segunda parte está destinada a señalar los principios que inspiran al documento, el alcance internacional y regional, los objetivos de desarrollo relacionados con el bienestar de toda la población y los objetivos humanitarios vinculados al respeto por los derechos humanos en esta materia. El tercer apartado contiene recomendaciones para la acción propuestas en virtud de los efectos que el envejecimiento tiene en el desarrollo y las esferas de preocupación de las personas de edad.

Las recomendaciones contemplan con especial detalle los derechos relativos a: salud y nutrición (rec. 1 a 17); la protección de los consumidores ancianos (rec. 18); vivienda y medio ambiente (rec. 19 a 24); el papel

6 Respecto de la tipificación de las fuentes con carácter de "espectáculo o propaganda”, puede verse Ciuro Caldani $(1983,1988)$. 
de la familia (rec. 25 a 29); el bienestar social (rec. 30 a 35); la seguridad del ingreso y empleo (rec. 36 a 43) y la educación en la vejez (rec. 44 a 50). Además, el texto hace referencia a la necesidad de implementar instrumentos que fomenten el sostenimiento de políticas y programas de acción (rec. 51 a 62). En tanto que, por último, establece recomendaciones para la ejecución de este Plan. Para lo cual, señala cuál es el papel que se espera de los gobiernos para cumplir con estos cometidos, la importancia de la cooperación internacional y regional y la necesidad de realizar exámenes y evaluaciones permanentes de su grado de aplicación (ASAMBLEA . . . , 1982).

En síntesis, el Plan de Viena establece que:

Sus metas principales son fortalecer la capacidad de los países para abordar de manera efectiva el envejecimiento de su población y atender a las preocupaciones y necesidades especiales de las personas de más edad, y fomentar una respuesta internacional adecuada a los problemas del envejecimiento mediante medidas para el establecimiento del nuevo orden económico internacional y el aumento de las actividades internacionales de cooperación técnica, en particular entre los propios países en desarrollo (ASAMBLEA ..., 1982, p. 2).

Sus objetivos comprenden:

a) Fomentar la comprensión nacional e internacional de las consecuencias económicas, sociales y culturales que el envejecimiento de la población tiene en el proceso de desarrollo;

b) Promover la comprensión nacional e internacional de las cuestiones humanitarias y de desarrollo relacionadas con el envejecimiento;

c) Proponer y estimular políticas y programas orientados a la acción y destinados a garantizar la seguridad social y económica a las personas de edad, así como darles oportunidades de contribuir al desarrollo y compartir sus beneficios;

d) Presentar alternativas y opciones de política que sean compatibles con los valores y metas nacionales y con los principios reconocidos internacionalmente con respecto al envejecimiento de la población y a las necesidades de las propias personas de edad; $y$ 
e) Alentar el desarrollo de una enseñanza, una capacitación y una investigación que respondan adecuadamente al envejecimiento de la población mundial y fomentar el intercambio internacional de aptitudes y conocimiento en esta esfera. (ASAMBLEA ..., 1982, p. 2).

Por su parte, el Plan de Acción Internacional de Madrid sobre el Envejecimiento, de 2002 (ASAMBLEA . . . 2002), retoma algunas cuestiones señaladas por el documento anterior y amplía otras. Así, por ejemplo, en el texto se vuelve a resaltar la necesidad de desarrollar políticas sociales y jurídicas que asuman de manera plena las cuestiones derivadas de los cambios demográficos. Concretamente expresa que:

5. El envejecimiento de la población pasará a ser una cuestión de primordial importancia en los países en desarrollo que, según se proyecta, envejecerán rápidamente en la primera mitad del siglo XXI. Se espera que para 2050 el porcentaje de personas de edad aumentará del $8 \%$ al 19\%, mientras que el de niños descenderá del 33\% al 22\%. Este cambio demográfico plantea un problema importante en materia de recursos. Aunque los países desarrollados han podido envejecer gradualmente, se enfrentan a problemas resultantes de la relación entre el envejecimiento y el desempleo y la sostenibilidad de los sistemas de pensiones, mientras que los países en desarrollo afrontan el problema de un desarrollo simultáneo con el envejecimiento de la población (ASAMBLEA ..., 2002, p. 3).

Por ello, más adelante el texto señala que:

8. Es indispensable integrar el proceso del envejecimiento mundial, que está en curso de evolución, en el proceso más amplio del desarrollo. Las políticas sobre el envejecimiento deben ser examinadas cuidadosamente desde una perspectiva de desarrollo que incluya el hecho de la mayor duración de la vida y con un punto de vista que abarque toda la sociedad, tomando en cuenta las recientes iniciativas mundiales y los principios orientadores establecidos en 
importantes conferencias y reuniones en la cumbre de las Naciones Unidas (ASAMBLEA . . . , 2002, p. 3-4).

\section{El Plan de Acción Internacional sobre el Envejecimiento del 2002 plantea varios temas centrales, vinculados a los objetivos que a continua- ción se detallan:}

a) La plena realización de todos los derechos humanos y libertades fundamentales de todas las personas de edad.

b) El envejecimiento en condiciones de seguridad, lo que entraña reafirmar el objetivo de la eliminación de la pobreza en la vejez sobre la base de los Principios de las Naciones Unidas en favor de las personas de edad.

c) La habilitación de las personas de edad para que participen plena y eficazmente en la vida económica, política y social de sus sociedades, incluso mediante trabajo remunerado o voluntario.

d) Las oportunidades de desarrollo, realización personal y bienestar del individuo en todo el curso de su vida, incluso a una edad avanzada, por ejemplo, mediante la posibilidad de acceso al aprendizaje durante toda la vida y la participación en la comunidad, al tiempo que se reconoce que las personas de edad no constituyen un grupo homogéneo.

e) La garantía de los derechos económicos, sociales y culturales de las personas de edad, así como de sus derechos civiles y políticos, y la eliminación de todas las formas de violencia y discriminación contra las personas de edad.

f) El compromiso de reafirmar la igualdad de los sexos en las personas de edad, entre otras cosas, mediante la eliminación de la discriminación por motivos de sexo.

g) El reconocimiento de la importancia decisiva que tienen para el desarrollo social las familias y la interdependencia, la solidaridad y la reciprocidad entre las generaciones.

h) La atención de la salud, el apoyo y la protección social de las personas de edad, incluidos los cuidados de la salud preventivos y de rehabilitación.

i) La promoción de una asociación entre el gobierno, a todos sus niveles, la sociedad civil, el sector privado y las propias 
personas de edad en el proceso de transformar el Plan de Acción en medidas prácticas.

j) La utilización de las investigaciones y los conocimientos científicos y el aprovechamiento del potencial de la tecnología para considerar, entre otras cosas, las consecuencias individuales, sociales y sanitarias del envejecimiento, en particular en los países en desarrollo.

k) El reconocimiento de la situación de las personas de edad pertenecientes a poblaciones indígenas, sus circunstancias singulares y la necesidad de encontrar medios de que tengan una voz eficaz en las decisiones que les afectan directamente (ASAMBLEA ... , 2002, p. 4-5).

Para cumplir estos propósitos, el Plan elabora una serie de recomendaciones destinadas a garantizar con eficacia el respeto de los derechos fundamentales de las personas ancianas (ASAMBLEA . . . , 2002). A tal fin, el documento propone la implementación de programas de acción, con arreglo a tres orientaciones prioritarias: las personas de edad y el desarrollo; el fomento de la salud y el bienestar hasta llegada la vejez y la creación de entornos propicios y favorables.

En la primera orientación se tiene en cuenta, de modo especial: 1) la participación activa en la sociedad y en el desarrollo; 2) el empleo y el envejecimiento de la fuerza de trabajo; 3) el desarrollo rural, migración y urbanización; 4) el acceso al conocimiento, la educación y la capacitación; 5) la solidaridad intergeneracional; 6) la erradicación de la pobreza; 7) la seguridad de los ingresos, protección social y prevención de la pobreza; 8) las situaciones de emergencia.

En la orientación prioritaria referida al fomento de la salud y el bienestar en la vejez se contempla: 1) el fomento de la salud y el bienestar durante toda la vida; 2) el acceso universal y equitativo a los servicios de atención de la salud; 3) las personas de edad y el VIH/SIDA; 4) la capacitación de los proveedores de servicios de salud y de los profesionales de la salud; 5) las necesidades relacionadas con la salud mental de las personas de edad; 6) las personas de edad y las discapacidades.

En la orientación vinculada con la creación de un entorno propicio y favorable se aborda la cuestión de: 1) la vivienda y las condiciones de vida; 2) la asistencia y apoyo a las personas que prestan asistencia; 3) el abandono, maltrato y violencia. Además, como en el plan anterior, éste prevé una sección destinada a la aplicación y seguimiento del programa, con medidas 
destinadas al plano nacional e internacional y a la supervisión, examen y actualización en el plano mundial.

Ahora bien, a pesar de este proceso internacional de positivacion, en el Derecho Interno argentino no se ha desarrollado todavía una legislación nacional suficiente para acompañar la producción normativa internacional y consagrar de manera específica los derechos fundamentales de los ancianos. Camino que sí parece haber transitado el Derecho Interno de Brasil, mediante la puesta en vigencia del Estatuto do Idoso y los decretos reglamentarios correspondientes.

Sin embargo, haciendo una interpretación extensiva de nuestra Constitución, puede advertirse también que, a partir de su última reforma - en 1994 -, ella ha consagrado tres tipos de derechos fundamentales para los ancianos. Derechos de Autonomía, referidos básicamente a la vida y a la salud, a las libertades, a la igualdad y a la propiedad. Derechos de Participación: al trabajo, a la asociación, a la recreación, al ocio y uso del tiempo libre. Y Derechos de Prestación o Crédito: vinculados con la seguridad social; es decir, el derecho a pensión, jubilación; con el desarrollo y a la educación?.

En efecto, estos derechos ya receptados por nuestra Constitución desde el siglo XIX fueron sin duda fortalecidos por la inclusión de los Pactos, Tratados y Declaraciones internacionales del nuevo artículo 75 inc. 22, según vimos, cuando dice que:

[ ... ] La Declaración Americana de los derechos y Deberes del Hombre, la Declaración Universal de Derecho Humanos; la Convención Americana sobre Derechos Humanos; el Pacto Internacional de Derechos Económicos, Sociales y Culturales, el Pacto Internacional de Derechos Civiles y Políticos y su Protocolo Facultativo; la Convención sobre la Prevención y la Sanción del Delito de Genocidio; la Convención Internacional sobre la Eliminación de todas las Formas de Discriminación Racial; la Convención Internacional sobre la Eliminación de todas las Formas de Discriminación de la Mujer; la Convención contra la Tortura, y otros Tratos o Penas Crueles, Inhumanas o Degradantes; la Convención sobre los Derechos del Niño; en las condiciones de su vigencia, tienen jerarquía constitucional, no derogan artículo alguno de la Primera Parte de esta Constitución y deben entenderse com-

7 Para esta clasificación seguimos el criterio utilizado por el profesor Prieto Sanchís (1990).

Estud. interdiscip. envelhec., Porto Alegre, v. 13, n. 1, p. 7-26, 2008. 
plementarios de los derechos y garantías por ella reconocidos [... ] (ARGENTINA, 2000, p. 26).

Así en Argentina, junto al "bloque de constitucionalidad” de los textos internacionales de Derechos Humanos mencionados, la Constitución Nacional ofrece al Derecho de la Ancianidad la posibilidad de contar con dos tipos de normas jurídicas para su configuración. Un grupo está referido a los derechos humanos que resultan directamente aplicables por su rango constitucional, de jerarquía, incluso, superior a las leyes de la Nación. Ello ocurre respecto de los preceptos del art. 75 inc. 22, ya mencionadas. Mientras que el segundo se compone de documentos que funcionan como criterios jurídicos de interpretación; muy útiles, por ejemplo, para la labor judicial. El Plan de Acción de Viena de 1982 y el Plan de Madrid de 2002, como vimos, son ejemplos ilustrativos de este grupo. Ellos han sido firmados y receptados por nuestro país, en calidad de recomendaciones para el desarrollo de políticas y normativas gerontologicas.

En tanto rama transversal del mundo jurídico argentino, el Derecho de la Ancianidad se nutre también de las otras disciplinas que lo integran. Razón por la cual, además de destacar su vinculación con el Derecho Constitucional, se hace especialmente necesario subrayar su contacto con las instituciones propias del Derecho Civil, Administrativo, Comercial, Laboral, Tributario; Derecho Penal o Derecho Procesal, entre otras.

\section{Contenido del Derecho de la Ancianidad}

En Argentina, el escenario actual permite inclusive ir un poco más allá de lo afirmado hasta ahora. Nos habilita a pensar y a trabajar en favor de la construcción del Derecho de la Ancianidad, como una nueva especialidad. Como un campo jurídico autónomo, integrado por una realidad social particular: la vejez; por principios e instituciones normativas de contenido gerontológico y por criterios de justicia eficaces para la personalización de los ancianos y de las comunidades envejecientes. Esta nueva rama debe ocuparse de concretar la defensa de los derechos de las personas de edad respecto de su autonomía, tanto como en relación a sus cauces de participación social y a su calidad de receptor de beneficios estatales.

Así, en el marco de los derechos de autonomía, por ejemplo, es menester tratar: la cuestión de la capacidad de la persona anciana y la autonomía de su voluntad. El derecho a la vida - y a ser viejo -, a la salud y a la asistencia sanitaria; y el derecho a la integridad física y moral. La violencia y la discri- 
minación, con especial referencia al enfoque de género y a la problemática de las personas mayores que pertenecen a minorías raciales, sexuales o culturales. Los problemas derivados de la libertad y la comunicación y su relación con las demás generaciones. El papel de los medios de comunicación. Los derechos referidos a la libertad en el anciano (libertad de circulación, de expresión, etc.). Los derechos referidos a la comunicación (debida defensa en juicio, derecho a peticionar, inviolabilidad de la correspondencia, etc.). Es necesario estudiar la cuestión de la propiedad en la ancianidad. El derecho a la vivienda. El derecho de Habitación viudal. La temática de los Geriátricos. La Renta Vitalicia, el Usufructo o la Indivisión forzosa. También es importante abordar la temática del consumo y del acceso al crédito. Los derechos sucesorios.

Respecto de los derechos de participación, es oportuno trabajar sobre la problemática de la discapacidad y las barreras en la ancianidad. Los derechos y obligaciones de los ancianos discapacitados y de las instituciones. Los talleres protegidos. La cuestiones referidas a la familia, tales como: el derecho del anciano/a al matrimonio. El matrimonio mortis causa. El derecho de alimentos y de visita. La adopción y la tutela en la ancianidad. También, lo referido a la asociación, ocupación y trabajo. En especial, el derecho de asociación, el análisis de los Clubes y Centros de Jubilados. El derecho a la ocupación y al trabajo y los límites de estos derechos. También es importante estudiar la cuestión de la recreación en la ancianidad. El derecho al esparcimiento, al ocio y al descanso.

En el marco de los derechos de prestación se impone la exigencia de comprender todo aquello referente a la Seguridad Social en la ancianidad. Los sistemas provisionales. El derecho del seguro. La relación entre políticas sociales y derecho de la ancianidad, la pobreza, la soledad y el "asistencialismo”. Los nuevos modelos derivados de las redes de contención social, los asistentes gerontológicos y/o cuidadores de ancianos, el voluntariado y las Organizaciones No Gubernamentales (ONG). Así como también el desarrollo de las medidas de acción afirmativa o de discriminación inversa.

Por ultimo, urge asimismo completar este rico panorama con la inclusión del estudio integral de los Sistemas de Protección y Garantías vigentes en el Derecho argentino. Importante será reconocer las fortalezas y debilidades de la labor de las Instituciones del sistema de protección, tales como Instituto Nacional de Servicios Sociales para Jubilados y Pensionados (INSSJP), la Dirección Provincial de la Caja de Pensiones Sociales (Ley 5110). De las Obras sociales. De la Defensoría del Pueblo (Nacional, Provincial, Municipal). El Consejo Nacional del Menor y la Familia. La Dirección Provincial de la 
Tercera Edad. Las Secretarías de Promoción Social de las Municipalidades. La Escuela municipal de Gerontología de la ciudad de Rosario (Santa Fe) y los Organismos de Defensa del Consumidor. Así como también cabe desarrollar un estudio nuevo de los recursos procesales y métodos alternativos de solución de conflictos, en los cuales participe cualquier persona de edad o estén referidos a sus temáticas.

La Facultad de Derecho de la Universidad Nacional de Rosario, Argentina, cuenta ya con una destacada trayectoria en la construcción de este campo jurídico. Desde 1998, esta Casa ha contado con un Área de Investigaciones Interdisciplinarias en esta materia. Circunstancia que permitió erigir en el 2001, el primer Centro de Investigaciones en Derecho de la Ancianidad de este país. Como resultado de esta labor ha podido concretarse, además, el dictado de una asignatura de grado destinada íntegramente al Derecho de la Ancianidad. Su desarrollo se ha iniciado en el año 2005, con gran éxito, constituyendo también una experiencia inédita para Argentina.

\section{Conclusiones}

En este trabajo se ha intentado reseñar un panorama general acerca de la problemática de la vejez en el Derecho Argentino. Según vimos, la ancianidad resulta todavía una cuestión escasamente abordada en nuestro sistema. No obstante en la última década se vienen desarrollando importantes esfuerzos en aras de mitigar esta situación. Uno de ellos los constituye, sin duda, la reciente creación del "Derecho de la Ancianidad”. Rama jurídica transversal y especial, en atención a las características particulares que presentan sus sujetos titulares. Su contenido se halla condicionado por tres principios básicos que urgen su cumplimiento en esta materia: el principio de continuidad vital, el de privacidad y el de participación.

Por otra parte, el artículo ha permitido realizar un breve recorrido respecto de las razones materiales que contribuyeron a su configuración. Ha posibilitado el planteo de la autonomía formal de esta nueva rama, mediante el detalle de las fuentes normativas primarias que la componen. Así como también se han descrito las problemáticas jurídicas más relevantes que atraviesan las ramas jurídicas tradicionales, tales como el Derecho Constitucional, Administrativo, Civil, Penal, Procesal, entre otras. Ellas están referidas a los derechos fundamentales de autonomía, participación y crédito. 


\title{
THE PROBLEM OF OLD AGE IN ARGENTINE LAW: reasons for constructing an elder law
}

\begin{abstract}
Law incorporation into the field of Gerontology has been, in fact, very recent. Only 25 years ago the development of process of formalization of human rights for elder people it has began all over the world, with integral character. This fact, with the increasing social needs that shows the elder population in Argentina has been responsible for the recent creation of one transversal juridical specialization, which is called: Elder Law. Life span account, privacy and participation constitute its mains principles, being source of the rights to autonomy, participation and credit of human rights of elder people in Argentine Law.
\end{abstract}

Keywords: Old age. Argentine Law. Elder Law. Autonomy, participation and credit human rights of elder people.

\section{REFERENCIAS}

ARGENTINA. Constitución Nacional Argentina. Ed. corregida y actualizada por R. Sukerman. Rosario: Fundación Ross, 2000.

ASAMBLEA MUNDIAL SOBRE EL ENVEJECIMIENTO. Plan de Acción Internacional de Viena sobre el Envejecimiento. Viena, 1982. Disponible en: <http://200.29.21.4/ gerontol/postnuke/docs/planviena.doc>. Acceso en: 6 marzo 2006.

ASAMBLEA MUNDIAL SOBRE EL ENVEJECIMIENTO. Plan de Acción Internacional Madrid sobre el Envejecimiento. Madrid, 2002. Disponible en: <http://200.29.21.4/ gerontol/postnuke/pdf/Plandeaccion2002.pdf>. Acceso en: 6 marzo 2006.

ASIEL, Monique. Cuidados médicos y sanitarios. In: INSTITUTO NACIONAL DE SERVICIOS SOCIALES. La Tercera Edad en Europa. 2. ed. Madrid, 1991. P. 83 et seq. 
BAZO, María Teresa. La vejez como problema social. In: SÁNCHEZ VERA, Pedro (Ed.). Sociedad y Población Anciana. Murcia: Universidad de Murcia, 1993. P. 181-191.

BEAUVOIR, Simone de. La Vejez. Trad. Aurora Bernárdez. Barcelona: Edhasa, 1989.

BOBBIO, Norberto. El Tiempo de los Derechos. Trad. Rafael de Asís Roig. Madrid: Sistema, 1991.

BROCK, Dan W. Justice, Health Care and the Elderly. Philosophy \& Public Affairs, Ames, v. 18, n. 3, p. 297-312, Summer 1989.

CIURO CALDANI, Miguel Ángel. Comparación jusfilosófica del Derecho de Menores y el Derecho de la Ancianidad. Investigación y Docencia, Rosario, n. 25, p. 7 et seq., 1995a.

CIURO CALDANI, Miguel Ángel. Derecho de la Ancianidad. Investigación y Docencia, Rosario, n. 20, p. 39 et seq., 1992.

CIURO CALDANI, Miguel Ángel. Filosofía jurídica de la marginalidad, condición de penumbra de la postmodernidad. Investigación y Docencia, Rosario, n. 25, p. 26 et seq., 1995b.

CIURO CALDANI, Miguel Ángel. La Conjetura del Funcionamiento de las Normas Jurídicas: metodología jurídica. Rosario: FIJ, 2000.

CIURO CALDANI, Miguel Ángel. Las fuentes de las normas. Zeus, Rosario, t. 32, p. D-103 et seq., 1983.

CIURO CALDANI, Miguel Ángel. Lecciones de Historia de la Filosofía del Derecho. Rosario: FIJ, 1994.

CIURO CALDANI, Miguel Ángel. Panorama trialista de la Filosofía del Derecho en la Postmodernidad. Boletín del Centro de Investigaciones de Filosofía Jurídica y Filosofía Social, Rosario, n. 19, p. 9-96, 1995c. 
CIURO CALDANI, Miguel Ángel. Reflexiones sobre las fuentes del Derecho Internacional Privado. Boletín del Centro de Investigaciones de Filosofía Jurídica de Filosofía Social, Rosario, n. 10, p. 35-38, 1988.

DABOVE, María Isolina. La condición de la mujer anciana desde la perspectiva del Derecho. Revista Bioética y Bioderecho, Rosario, n. 1, p. 49 et seq., 1996.

DABOVE, María Isolina. Los Derechos de los Ancianos. Buenos Aires: Ciudad Argentina, 2002.

DANIELS, Norman. Am I my Parents' Keeper? An essay on justice between the young and the old. New York: Oxford University Press, 1988.

DANIELS, Norman. Health-care and Needs in Distributive Justice. Philosophy \& Public Affairs, Ames, v. 10, n. 2, p. 146-179, Spring 1981.

ESPAÑA. Ministerio de Asuntos Sociales. Instituto Nacional de Servicios Sociales. La Tercera Edad en España: necesidades y demandas. Madrid, 1990.

FOKKEMA, Tineke; UNIVERSIY, Peter. Utilización de los servicios de salud por parte de las personas mayores: ¿es la sustitución un instrumento para economizar los costes de cobertura? In: UNIÓN DEMOCRÁTICA DE PENSIONISTAS Y JUBILADOS DE ESPAÑA. Sociología de la Vejez. Madrid, 1992. P. 143-168.

FROMM, Erich. El Miedo a la Libertad. Trad. Gino Germani. Barcelona: Paidós, 1993.

GLASTONBURY, Brian. Nuevas tecnologías e información para las personas mayores. In: UNIÓN DEMOCRÁTICA DE PENSIONISTAS Y JUBILADOS DE ESPAÑA. Sociología de la vejez. Madrid, 1992. P. 177-185.

GOLDSCHMIDT, Werner. Introducción Filosófica al Derecho. 6. ed. Buenos Aires: Depalma, 1987.

GRACIA, Diego. Fundamentos de Bioética. Madrid: Eudema, 1989. 
LÓPEZ ARANGUREN, Eduardo. Los derechos de la tercera edad. Derechos y Libertades, Getafe, n. 2, p. 15-32, 1993.

LÓPEZ JIMÉNEZ, Juan José. La jubilación: opción o imposición social. Revista Española de Investigaciones Sociológicas, Madrid, n. 60, p. 91-126, 1992.

MENDEZ COSTA, María Josefa. Los ancianos en la legislación civil. La Ley, Buenos Aires, t. 1983-A, p. 318 et seq., 1983.

NINO, Carlos S. Ética y Derechos Humanos: un ensayo de fundamentación. Barcelona: Ariel, 1989.

PENNING, Margaret. Health, Social Support, and the Utilization of Health Services Among Older Adults. Journal of Gerontology: Social Sciences, Washington, v. 50B, n. 5, p. S330-S339, 1995.

PRIETO SANCHÍS, Luis. Estudios sobre Derechos Fundamentales. Madrid: Debate, 1990.

Recebido em: 07-11-2007

$1^{a}$ revisão: 14-03-2008

$2^{a}$ revisão: 09-07-2008

Aceite final: 14-07-2008 